\title{
Correction to: Study on Electrical Aging Characteristics of Fiber Sheath Materials in Power Transformer Oil
}

\author{
Lu Sun $^{1} \cdot$ Xiaozhou Fan ${ }^{2} \cdot$ Shuo Jiang ${ }^{2} \cdot$ Bowen Wang $^{2} \cdot$ Yunpeng Liu $^{2} \cdot$ Shuguo Gao ${ }^{1} \cdot$ Lingming Meng $^{1}$
}

Published online: 6 July 2020

(c) The Korean Institute of Electrical Engineers 2020

\section{Correction to: \\ Journal of Electrical Engineering \& Technology (2019) 14:323-330 \\ https://doi.org/10.1007/s42835-018-00041-5}

In the acknowledgement one project number has been changed:

This work was supported by the Science and Technology Project of State Grid Corporation of China (5204DY16000P), the Fundamental Research Funds for the Central Universities (2016XS93) and the National Natural Science Foundation of China (51407074).

Publisher's Note Springer Nature remains neutral with regard to jurisdictional claims in published maps and institutional affiliations.

The original article can be found online at https://doi.org/10.1007/ s42835-018-00041-5.

Shuo Jiang

jiangshuo@ncepu.edu.cn

1 Hebei Electric Power Research Institute, State Grid Corporation of China, Shijiazhuang, China

2 State Key Laboratory of New Energy and Electric Power Systems, North China Electric Power University, Baoding, China 